\title{
Controlling supramolecular structures of drugs by light
}

Johannes Wiest $^{\mathrm{a}}$, Josef Kehrein ${ }^{\mathrm{a}}$, Marco Saedtler ${ }^{\mathrm{a}}$, Klaus Schilling ${ }^{\mathrm{a}}$, Eleonora Cataldi ${ }^{\mathrm{a}}$, Christoph A. Sotriffer $^{\mathrm{a}}$, Ulrike Holzgrabe ${ }^{\mathrm{a}}$, Tim Rasmussen ${ }^{\mathrm{b}}$, Bettina Böttcher ${ }^{\mathrm{b}}$, Mark Cronin-Golomb ${ }^{\mathrm{c}}$, Matthias Lehmann $^{\mathrm{d}}$, Nathalie Jung ${ }^{\mathrm{e}}$, Mike Winbergs ${ }^{\mathrm{e}}$, Lorenz Meinel ${ }^{\mathrm{*}}{ }^{\mathrm{a}}$.

${ }^{\text {a }}$ Institute of Pharmacy and Food Chemistry, University of Würzburg, Am Hubland, 97074 Würzburg, Germany

${ }^{\mathrm{b}}$ Department of Biochemistry, Rudolf Virchow Center, Josef-Schneider-Straße 2, 97080 Würzburg, Germany

${ }^{\mathrm{c}}$ Biomedical Engineering, Tufts University, Colby Street 4, 01867 Medford, MA

${ }^{d}$ Institute of Organic Chemistry, University of Würzburg, Am Hubland, 97074 Würzburg, Germany

${ }^{\mathrm{e}}$ Institute of Pharmaceutical Technology and Buchmann Institute for Molecular Life Sciences, Goethe University, Max-von-Laue-Straße 15, 60438 Frankfurt a. Main, Germany

${ }^{\mathrm{f}}$ Helmholtz Institute for RNA-based Infection Research (HIRI), Josef-Schneider-Straße 2, 97080 Würzburg, Germany.

* corresponding author

Keywords: salt design; light responsive; poorly water soluble drug; NMR; micelle

ABSTRACT: Controlling physicochemical properties of lightunresponsive drugs - by light, prima facie, a paradox approach. We expanded light control by ion-pairing light-unresponsive salicylate or Ibuprofen to photo-switchable azobenzene counterions thereby reversibly controlling supramolecular structures, hence the drugs' physicochemical and kinetic properties. The resulting ion-pairs photo-liquefied into room temperature ionic liquids under ultraviolet light. Aqueous solutions showed trans-cis dependent supramolecular structures under light with wormlike aggregates decomposing into small micelles and vice-versa. Light control allowed for permeation through membranes of $c i s-$ Ibuprofen ion pairs within 12 hours in contrast to the trans ion pairs requiring 72 hours. In conclusion, azobenzene ion-pairing expands light-control of physicochemical and kinetic properties to otherwise light-unresponsive drugs.

The experiments reported here addressed the hypothesis that the physical-pharmaceutical properties of light unresponsive drugs can be reversibly controlled after ion-pairing to photoswitchable azobenzene counterions. Azobenzenes, first described by Eilhard Mitscherlich in 1834, combine high quantum yields with trans-cis isomerization in response to illumination with different wavelengths of light. ${ }^{1-2}$ The photochromism of azobenzenes has been successfully applied in photo-switching of protein conformation ${ }^{3}$, photo-pharmacological application $^{4-5}$, drug nanopumps ${ }^{6}$, and in ion-pairs for photo-responsive energy storage..$^{7-8}$

To target the optical control of light unresponsive drugs, we synthesized photoswitchable ammonium and phosphonium containing azobenzene counterions (referred to as $\mathrm{N}^{+}$or $\mathrm{P}^{+}$) and ion-paired these to bromide and salicylate, a basic structure from which many other therapeutics are developed (Figure 1A, Scheme S1-4, Figure S1-10).
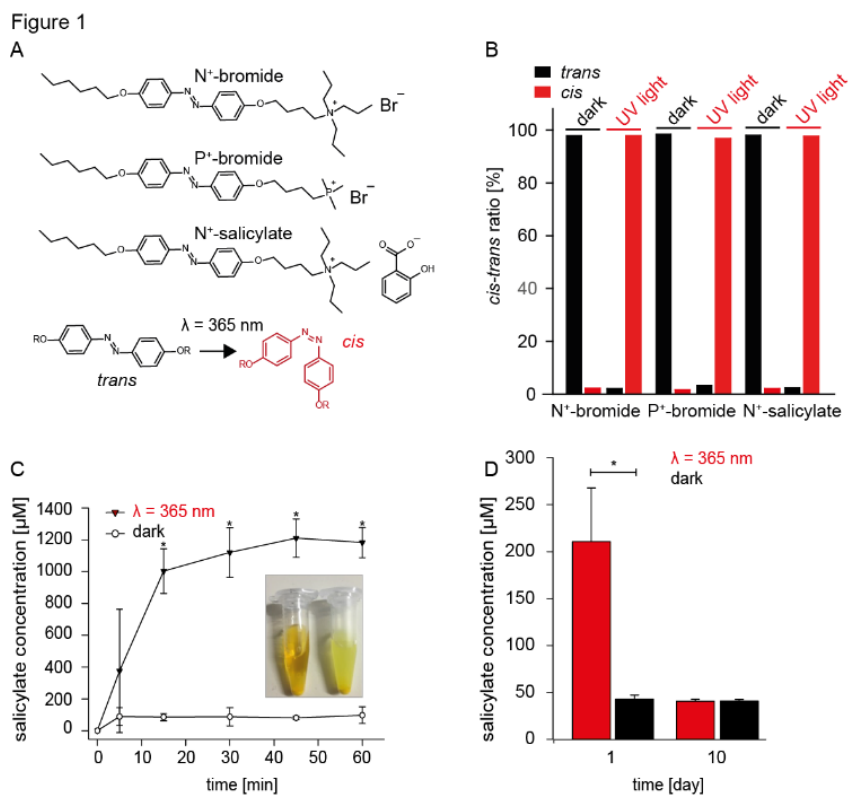

Figure 1. (A) Chemical structure of the photoswitchable salts $\mathrm{N}^{+}$-bromide, $\mathrm{P}^{+}$-bromide, $\mathrm{N}^{+}$-salicylate and scheme of the trans to cis isomerization of the azobenzene core unit when exposed to UV light. (B) Cis-to-trans ratio when exposed to UV light for 15 minutes or left in dark $(n=1)$. (C) Apparent salicylate solubility of the $\mathrm{N}^{+}$-salicylate ion-pair during UV exposure for the first 15 minutes and thereafter $(n=3)$. UV light exposure resulted in a clear solution in contrast to samples stored in dark. (D) Apparent solubility of salicylate when ion paired as $\mathrm{N}^{+}$-salicylate salt one day and 10 days after UV exposure $(n=3)$. Data is shown as mean \pm standard deviation; comparisons were by Student $t$-Test; $\mathrm{p} \leq 0.05$ was considered statistically significant and indicated by an asterisk.

The salts isomerized trans to cis under UV light $(\lambda=365 \mathrm{~nm}$; 15 minutes of irradiation at $650 \mathrm{~mW} / \mathrm{cm}^{2}$ in a distance of $5 \mathrm{~cm}$; 
Figure 1B, Figure S11) resulting in solid-to-liquid phase transition at room temperature (Video S1) and a more than 10-fold increased apparent solubility in water (Figure 1C). Salicylate's apparent solubility remained increased for one day and returned to levels of the thermodynamic solubility within 10 days after irradiation, respectively (Figure 1D). We now integrated Ibuprofen (2-(4-isobutylphenyl)propionic acid) - a non-steroidal, anti-inflammatory drug - into azobenzene ion-pairs. Both Ibuprofen ion-pairs formed an ionic salt, with the triethylammonium Ibuprofenate salt $\left(\mathrm{N}^{+}\right.$-Ibuprofen; the structure of the azobenzene is in Figure 1A) being liquid at room temperature (room temperature ionic liquid) and the trimethylphosphonium Ibuprofenate ( $\mathrm{P}^{+}$-Ibuprofen) being a crystalline solid at room temperature (Figure S12, Figure 2A, Scheme S4). We selected the solid $\mathrm{P}^{+}$-lbuprofen for further characterization as of its transition of aggregate states with light. The trans-isomer of the $\mathrm{P}^{+}$-lbuprofen crystalline solid powder (melting point $107^{\circ} \mathrm{C}$; (Figure S13)) photo-switched into an amorphous liquid (room temperature ionic liquid) following UV light exposure (glass transition temperature $-17^{\circ} \mathrm{C}$, Figure 2B, Figure S14). Photo-switching resulted in the separation of water suspensions into a less viscous upper phase and a viscous amorphous gel phase beneath. Both phases responded to UV light exposure with a color switch from yellow to intense red (Figure 2C). The lower gel structure layer was further studied by wideand small-angle X-ray scattering (WAXS/SAXS, Figures S1516). In dark (trans) a broad low intensity signal at $3.4 \mathrm{~nm}$ (correlation length of $3.5 \mathrm{~nm}$ (Scherrer formula; Figure S15)) and a much weaker signal at $1.5 \mathrm{~nm}$ was observed, indicating a double layer arrangement with antiparallel intercalated ion pairs with a length of $2.8-2.9 \mathrm{~nm}$. Each double layer was separated by a layer of water with a thickness of about $0.5 \mathrm{~nm}$ (representing 2-3 water molecules). After 75 min of exposure to UV light, most of the water (about 70\%) was squeezed out from the lower gel layer. Two sharp and more intense reflections became visible indicating a higher correlation length, thus the formation of a periodic, ordered structure. A qualitative interpretation of these two reflections with non-equidistant ratio suggested that supramolecular assembly was not just a simple layered structure but was more complex. In fact, as water was macroscopically separated throughout the structure (visible observation), we expect nanosegregation of aliphatics and the respective ion pairs dominating self-assembly in the bulk after irradiation. Back-conversion of the cis-azobenzene in the trans isomer over time reverted the process, i.e. water was again integrated in the gel structure (observed visually) and the thermodynamically stable structure was attained again as seen before by others. ${ }^{9-10}$ However, the limited data set (SAXS and non-oriented multi-domain samples) allows for qualitative interpretation but not for deriving a precise structure model of the supramolecular assembly. Figuratively, the gel layer formed photo-switchable molecular sponges experiencing structural transition in response to light - accompanied by corresponding color changes from yellow (trans) to dark red (cis). The structural effects relaxed over several hours as shown by time-dependent SAXS measurements (Figure S16). Without an external stimulus the cis isomer reverts spontaneously to the more thermodynamic stable trans isomer and the structure takes up the water again to form the gel structure. Similar light-controlled molecular sponges were reported before for organogels 910 and now for hydrogels formed by ion-paired drugs. For the less viscous upper phase, UV light exposure for 15 minutes increased the apparent Ibuprofen solubility by 2 -fold in water and this was stable for 10 days (Figure 2 D). $99 \%$ or $3 \%$ of the ion-pairs were in trans form when stored in dark or after UV light exposure, respectively (Figures S17-18). Altered steric molecular structure on cis formation leads to remarkable changes on its physical properties. The angular geometry acquired by illumination, through the new arrangement of aromatic rings, causes dipole moment increment (from 0 to $3.0 \mathrm{D}$ ) for the azobenzene core, so that the intermolecular forces, such as van der Waals interaction, $\pi-\pi$ stacking and lattice energy are weakened. ${ }^{9}$

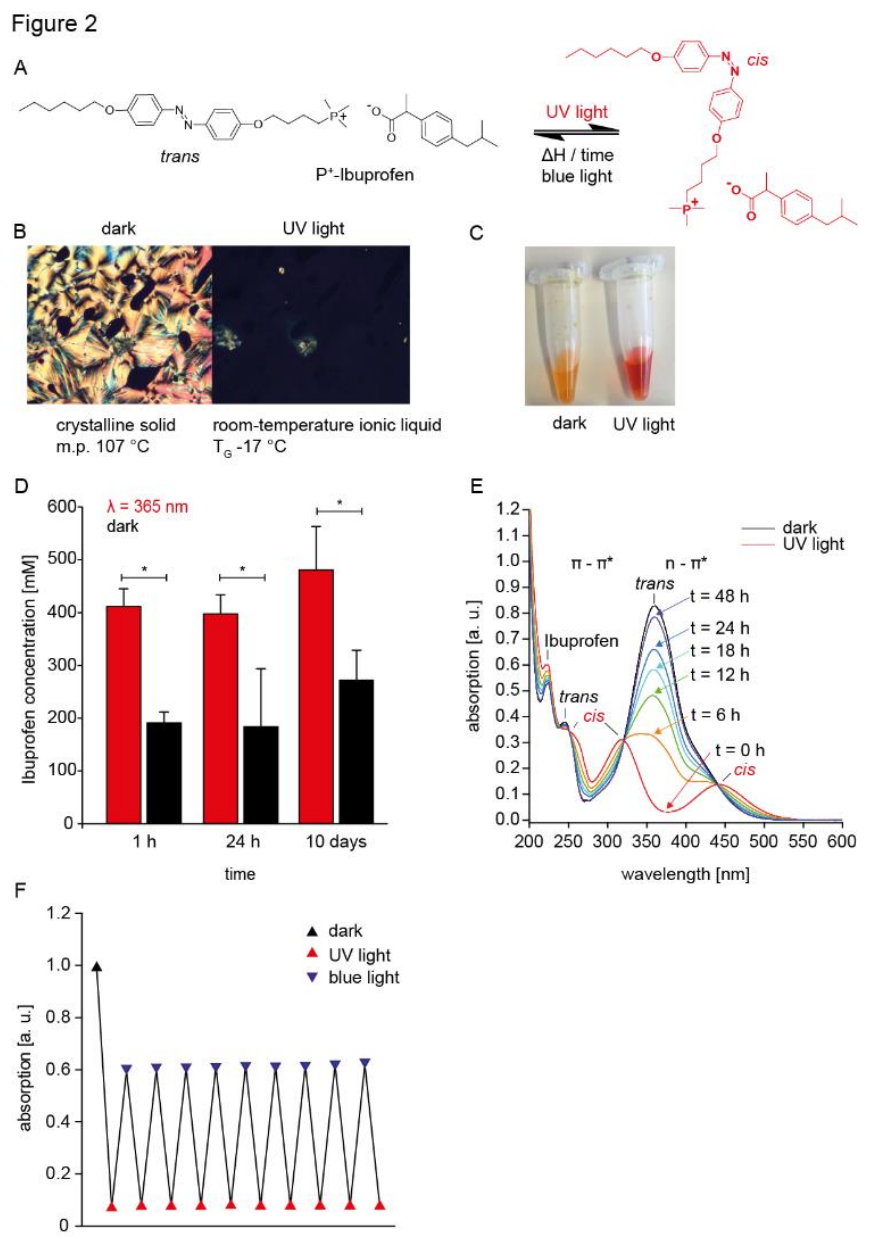

Figure 2. (A) Chemical structure of the photoswitchable $\mathrm{P}^{+}$-lbuprofen salt. (B) Polarizing microscope images of the solid, crystalline salt and the amorphous, room-temperature ionic liquid after UV exposure $(\lambda=365 \mathrm{~nm})$. (C) In water, the lbuprofen ion-pair turned from an orange suspension into a red hydrogel after UV light irradiation and shaking for 1 hour. (D) Apparent solubility of Ibuprofen in the supernatant with and without UV light irradiation $(\mathrm{n}=3)$. All samples were stored in dark and analyzed again after $24 \mathrm{~h}$ and 10 days later. Data is shown as mean \pm SD; comparisons were by Student's $t$-test; $p \leq 0.05$ was considered statistically significant and indicated by an asterisk. (E) UV-VIS spectra in water $(40 \mu \mathrm{M})$, in dark and after UV light exposure recorded at different time points. (F) Reversible photo-switching by repeated cycles of irradiation with UV and blue light (each lasting for 15 minutes).

At $40 \mu \mathrm{M}$ the UV-VIS spectrum of $\mathrm{P}^{+}$-azobenzene in trans state (dark; critical micelle concentration (CMC) $70 \mu \mathrm{M}$; Figure S19) had three distinct maxima in water reflecting the bands of the $\pi-\pi^{*}$ transition of Ibuprofen at $\lambda=224 \mathrm{~nm}$ and the $\pi-\pi^{*}$ transition and the $n-\pi^{*}$ transition at $\lambda=246$ and $360 \mathrm{~nm}$, respectively (Figure 2E). Following exposure to UV 
light the $\mathrm{P}^{+}$-azobenzene switched from trans to cis $(97 \%$ cis, Figure S18) resulting in a bathochromic shift of the $\pi-\pi^{*}$ (from 246 to $319 \mathrm{~nm}$ ) and the $n-\pi^{*}$ (from 360 to $444 \mathrm{~nm}$ ) transitions, respectively, while the $\pi-\pi^{*}$ transition of Ibuprofen remained unchanged (224 nm; Figure 2E). Increasing concentrations of the ion-pair in dark (trans) blue-shifted the $n-\pi^{*}$ band as reported for $\mathrm{H}$-aggregates (Figures S20-21). ${ }^{11}$ The cis form had a half-time of about 11.5 hours (Figure S22). Exposure to blue light $(\lambda=445 \mathrm{~nm})$ partially induced cis-trans isomerization and did not lead to photo-bleaching or any signs of degradation after 10 photoswitching cycles as indicated by identical UV spectra (Figure 2F) and confirmed by HPLC after one photoswitching cycle (Figure S17-18). The reversible phase transition from a crystalline solid to a room temperature ionic liquid after UV light exposure and the fast dissolution of the cis form are illustrated in supplementary videos (Videos S2, S3).

We now analyzed the assembly of supramolecular species following cis to trans isomerization of the $\mathrm{P}^{+}$-azobenzene ion-pair with Ibuprofen in water (Figure 3). Samples stored in dark (trans) had a polydispersity index (PDI) of about 0.29 (Figure 3A, Figure S23) with worm-, disk- and rodlike structures as observed by cryo-transmission electron microscopy (cryoTEM) (Figure 3B, Figure S29). These structures disappeared in response to UV light, being replaced by monodisperse or nearly monodisperse small mixed micelles (PDI 0.03) with a hydrodynamic diameter of about $5 \mathrm{~nm}$ (Figure 3B, Figure S24) and a 4-fold faster diffusion coefficient/Brownian velocity (Figure 3A, Figures S23-28). The colloidal solution's monodispersity peaked after about 6 hours in water and rearranged back into larger, diverse structures of the trans form after 24 to 72 hours resulting in PDI values of more than 0.3 (Figure 3A, Figures S25-28). Hence, these data sets suggested that along with the rearranged isomer $\left(\mathrm{t}_{1 / 2} \sim 11.5 \mathrm{~h}\right.$; Figure S22), soluble supramolecular structures formed. Future studies need to address the hypothesis that these supramolecular structures contribute to the observed recrystallization delay for up to 10 days In dark, the ${ }^{1} \mathrm{H}$ NMR resonances of the trans counterions' aryl and hexyl tail were broad (low tumbling rate, i.e. stiffer environment) and the methyl signals $(\mathrm{H}-1)$ of the polar phosphonium group were sharp. Similarly, the Ibuprofen's aryl and the alkyl signals were broad (small tumbling rate) suggesting its position in the stiffer environment between the trans $\mathrm{P}^{+-}$-azobenzenes (Figure 3C bottom, Figure S30). This was further corroborated by ${ }^{1} \mathrm{H},{ }^{1} \mathrm{H}$-NOESY spectra with a cross peak between the isobutyl group of lbuprofen and the aromatic signals of the trans $\mathrm{P}^{+}$-azobenzene indicating a molecular distance of lbuprofen to the trans isomer of less than $0.5 \mathrm{~nm}^{12}$ (Figure S31). Modelling studies also suggested an equilibrium including the formation of wormlike structures through ionic and cation- $\pi$ interactions between the drug and the trans isomer which were stable over time (Figures S32-33). Calculation of the packing parameter $\mathrm{P}$ of the trans isomer without Ibuprofen resulted in a $\mathrm{P}$ value of 0.17 (Table S2)..$^{13}$ The dark adapted cylindrical micelles predicted by the simulation and observed by cryo-TEM (trans; Figure $\mathbf{3 C}$ ) suggested reduced repulsion of the positively charged phosphonium groups when interacting with Ibuprofen's carboxylates. These densely packed micelles link to the observed high apparent solubility of the $\mathrm{P}^{+}$-azobenzene ion-pair with Ibuprofen in water. This transition from spherical to rodlike aggregates was previously reported for a similar system using cetyltrimethylammonium and the hydrophobic counterion p-ethyl-benzenesulfonate. ${ }^{14}$ Photoswitching of the $\mathrm{P}^{+}$-azobenzenes Ibuprofen ion-pairs into cis changed the interfacial association phenomena as reflected by increasing CMC and possibly an increasing surface excess (amount of the amphiphile per unit area of surface; Figure S19). This increase in hydrophilicity could hypothetically reflect the molecular bending of the cis-azobenzene core by which the charged heads of the alkyl chains move closer, hence the polar surface area increases. This increase in surface polarity favors interaction with the surrounding water, which is maximized by spherical structures and arguably explains the observed changes including $\mathrm{CMC}$ and as has been suggested before by others. ${ }^{15}{ }^{1} \mathrm{H}$ NMR resonances of the cis state resulted in sharper and less shifted signals of the lbuprofen, as compared to the trans isomer suggesting Ibuprofen being positioned between the $\mathrm{P}^{+}$-azobenzene but with a higher mobility / tumbling rate within the aggregates as compared to the trans state (Figure 3C, Figure S34). The ${ }^{1} \mathrm{H},{ }^{1} \mathrm{H}-\mathrm{NOESY}$ spectrum was less conclusive for the cis isomer (UV light) than the one measured for trans (dark) possibly resulting from the molecules switching back to trans during the experiment (Figure S35) and as indicated by distorted cross peaks due to ongoing re-organization into bigger supramolecular structures. In spite of these restrictions, the cross-peaks provided evidence that Ibuprofen was incorporated within the colloidal structures (Figure S35).

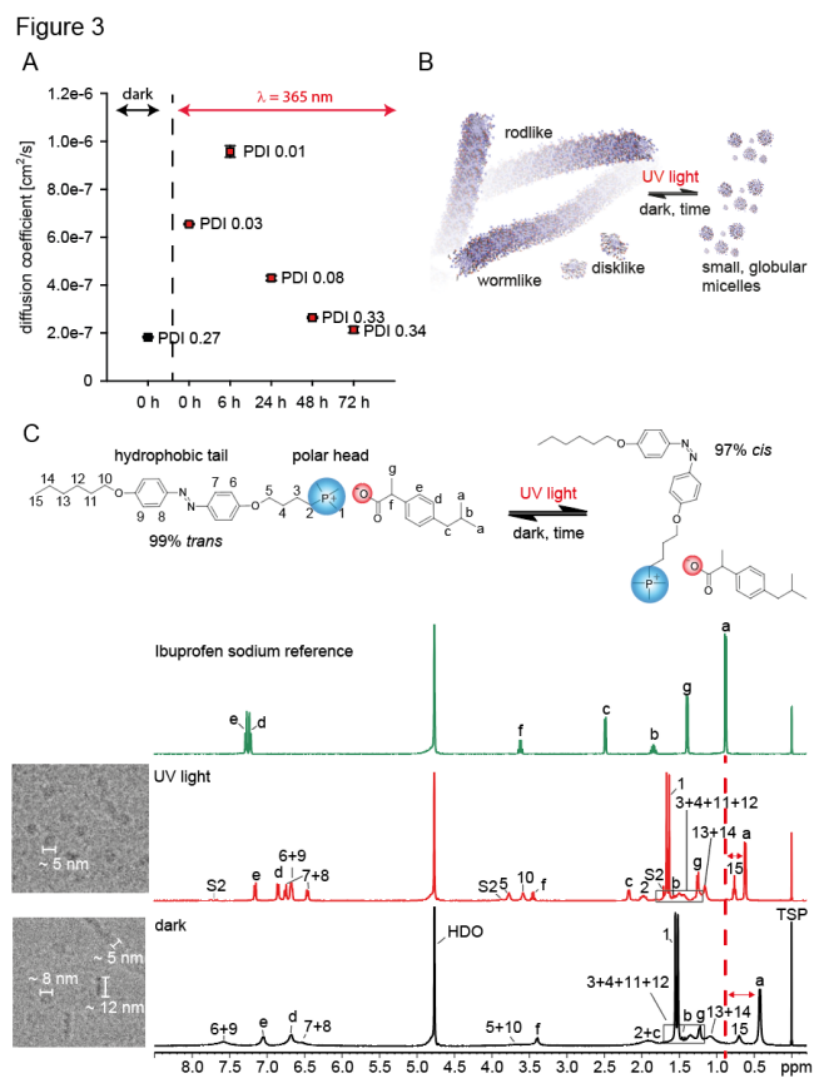

Figure 3. Supramolecular structures of $8 \mathrm{mM}$ aqueous solution of the $\mathrm{P}^{+}$ Ibuprofen ion-pair. (A) Average diffusion coefficient $\left[\mathrm{cm}^{2} / \mathrm{s}\right]$ of the colloidal species in dark and after UV light exposure. The numbers indicate the polydispersity index (PDI) (B) Scheme of supramolecular species in dark and after UV light irradiation. (C) Imaging of supramolecular species in dark and after UV light exposure by Cryo-TEM images and the ${ }^{1} \mathrm{H}$ NMR spectra of the corresponding state and Ibuprofen sodium for reference. 
The modelling experiments suggested that Ibuprofen did not diffuse from the colloids forming under UV light and suggesting stable micelle structures (Figure S36). We now studied the impact of the UV light induced changes of the $\mathrm{P}^{+}$-azobenzene Ibuprofen ion-pair on permeability. For that, the ion-pair was applied to synthetic model membranes of skin (Strat-M ${ }^{\circledR}$-membranes). After 3 minutes, the ion-pair in cis (UV light) permeated into the membrane and could not be wiped off in contrast to the trans-isomer which remained at the surface and was easily removed (Figure 4A; Video S4). This was also seen in cross-sections of the membranes taken 72 hours after application (Figure 4B). Both Ibuprofen ion-pairs penetrated significantly better than the sodium salt (Figure $4 \mathrm{C}$ ). The trans-isomer had a lag time of about 18 hours and reached equilibrium after 72 hours, whereas the cis-isomer readily penetrated through the model membrane and reached equilibrium in less than 12 hours following exponential patterns (Figure 4C). Future studies are needed to which extent these findings reflect differences in apparent solubility and/or differences in supramolecular assembly as of irradiation.

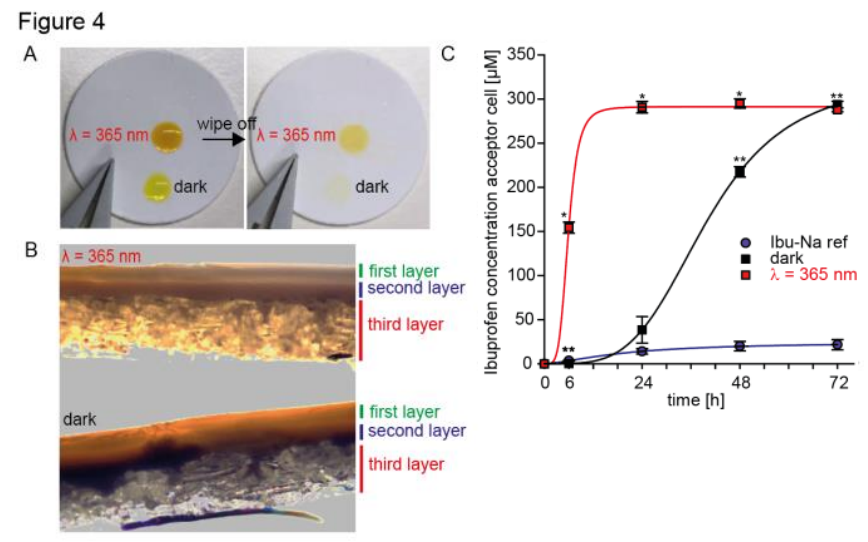

Figure 4. Permeability of $8 \mathrm{mM}$ aqueous solution of $\mathrm{P}^{+}-$Ibuprofen ion-pairs through membranes. (A) Top view on membranes after administration of a drop (left) and when wiped off three minutes later (right; Video S5). (B) Cross-section of membranes $72 \mathrm{~h}$ after exposure. (C) Permeation of lbuprofen ion pairs through membranes after UV light irradiation or stored in dark in comparison to lbuprofen sodium. Data is shown as mean $\pm \mathrm{SE}$; comparisons were by Student $t$-Test in comparison to Ibuprofen sodium; $p \leq$ 0.05 was considered statistically significant and indicated by an asterisk.

Lastly, we addressed the challenges of light penetration into tissues and cytotoxicity in light of future in vivo application. For that, exposure of the hydrogel (Figure 2C) was changed from UV-light $(\lambda=365 \mathrm{~nm})$ to ultrafast femtosecond mode-locked red light $(\lambda=730 \mathrm{~nm})$. The ion-pairs responded to irradiation at $\lambda=730 \mathrm{~nm}$ in focused ultrafast mode locked laser light by two photon absorption (TPA) through the azo moiety, an approach which has been previously demonstrated for drug delivery in an effort to reach deeper tissues by light ${ }^{16}$ or neural excitation. ${ }^{17}$ TPA rapidly impacted the structural features in the dark-adapted gel (Figure S37). This change was reversed by a focused laser at $\lambda=532 \mathrm{~nm}$ (Figure S37; Video S5). In these experiments, we did not quantify the response. However, experiments with solid crystals showed that complete liquefaction was achieved in a focal volume with $2.7 \mathrm{~mJ}$ using an $88 \mathrm{~mW} 80 \mathrm{MHz}$ repetition rate femtosecond beam at $\lambda=$ $730 \mathrm{~nm}$ center wavelength. $\left(2.7 \mathrm{~nJ} / \mathrm{mm}^{2}\right)$ per pulse (data not shown). Cytotoxicity studies with a spontaneously immortalized human keratinocyte cell line (HaCaT cells) indicated a half maximal inhibitory concentration $\left(\mathrm{IC}_{50}\right)$ of $7 \mu \mathrm{M}$ for the $\mathrm{N}^{+}$bromide salt and $18 \mu \mathrm{M}$ for $\mathrm{P}^{+}$-bromide salt (Figure S38). These $\mathrm{IC}_{50}$ values are in the range of e.g. benzethonium chloride (18 $\mu \mathrm{M}$; human fibroblasts), ${ }^{18}$ a cationic surfactant which is used in cosmetics and topical applications or in the range reported for the wound disinfectant octenidine dihydrochloride $(1.28 \mu \mathrm{M})$ when tested in human epidermal keratinocytes. ${ }^{19} 20$

In conclusion, light unresponsive drugs become light responsive through ion-pairing with photo-switchable azobenzene counterions. Light controlled the supramolecular structures and these structures in return controlled the physicochemical properties as they photo-controlled transport kinetics through model membranes of human skin. The opposite response under longer wavelength makes these processes reversible. The system offers TPA for future use within tissues and showed no or mild cytotoxicity. Future studies need to detail to which extent other successfully developed ionic liquid drugs may be paired with photo-responsive counterions ${ }^{21-22}$ Apart from expanding light control to light unresponsive drugs without the need for structure modification of the drug, application of this concept might be interesting in pharmaceutical processing (process as a liquid after UV light exposure/cis), shipping and storage(ship/store in dark/trans as a solid) or clinical application (light allows control of penetration depths and permeability of skin). As true for any new drug substance, preclinical safety studies and long term stability assessments are required before clinical use. Additionally, future in vivo studies should further detail the relevance of these findings for (pre-)clinical application.

\section{ASSOCIATED CONTENT}

\section{Supporting Information}

Synthesis, characterization, and further experimental outcome on the ion-pairs is provided in the supplementary information as pdf.

Five supplementary video movies are provided.

\section{AUTHOR INFORMATION}

\section{Corresponding Author}

Lorenz Meinel, Institute of Pharmacy and Food Chemistry, University of Würzburg, Am Hubland, 97074 Würzburg, lorenz.meinel@uni-wuerzburg.de.

\section{Author Contributions}

J.W. prepared the salts, performed the solubility experiments, Franz cell assays and the characterization by UV-VIS, DSC, NMR, ITC, XRPD, PLM and HPLC. J.K. and C.S. performed the molecular modeling studies, T.R. and B.B. the cryo-TEM imaging, M.S. the cytotoxicity studies, M.C.G. the scanning laser transformation and M.L. the SAXS/WAXS measurements. J.W, U.H. and L.M. planned the experiments. J.W., and L.M. analyzed all data and wrote the manuscript. All authors reviewed the manuscript.

\section{Notes}

The authors declare no competing financial interests. 


\section{ACKNOWLEDGMENT}

Financial support is acknowledged by the Bayerische Forschungsstiftung (grant \#AZ-1204-6 and \#DOK-179-17 to E.C.).

\section{REFERENCES}

1. Mitscherlich, E., Ueber das Stickstoffbenzid. Ann. Pharm. 1834, 12 (2-3), 311-314.

2. Bandara, H. M.; Burdette, S. C., Photoisomerization in different classes of azobenzene. Chem. Soc. Rev. 2012, 41 (5), 1809-25.

3. Sadovski, O.; Beharry, A. A.; Zhang, F.; Woolley, G. A., Spectral tuning of azobenzene photoswitches for biological applications. Angew. Chem. Int. Ed. Engl. 2009, 48 (8), 1484-6.

4. Rodríguez-Soacha, D. A.; Decker, M., Photopharmacology in Alzheimer's Disease. Adv. Ther. 2018, 1 (3), 1800037 (1of 9).

5. Hull, K.; Morstein, J.; Trauner, D., In Vivo Photopharmacology. Chem. Rev. 2018, 118 (21), 10710-10747.

6. Ju, H.; Zhang, Y.; Zhang, Y.; Song, G.; He, Y.; Zhang, X.; Liu, Y., A DNA-Azobenzene Nanopump Fueled by Upconversion Luminance for Controllable Intracellular Drug Release. Angew Chem Int Ed Engl 2019.

7. Bi, Y.; Wei, H.; Hu, Q.; Xu, W.; Gong, Y.; Yu, L., Wormlike micelles with photoresponsive viscoelastic behavior formed by surface active ionic liquid/azobenzene derivative mixed solution. Langmuir 2015, 31 (13), 3789-98.

8. Ishiba, K.; Morikawa, M.-a.; Chikara, C.; Yamada, T.; Iwase, K.; Kawakita, M.; Kimizuka, N., Photoliquefiable Ionic Crystals: A Phase Crossover Approach for Photon Energy Storage Materials with Functional Multiplicity. Angewandte Chemie 2015, 127 (5), 1552-1556.

9. Dugave, C.; Demange, L., Cis-trans isomerization of organic molecules and biomolecules: implications and applications. Chem Rev 2003, 103 (7), 2475-532.

10. Choi, Y.-J.; Kim, J.-T.; Yoon, W.-J.; Kang, D.-G.; Park, M.; Kim, D.-Y.; Lee, M.-H.; Ahn, S.-k.; Jeong, K.-U., Azobenzene Molecular Machine: Light-Induced Wringing Gel Fabricated from Asymmetric Macrogelator. ACS Macro Lett. 2018, 7 (5), 576-581.

11. Shimomura, M.; Ando, R.; Kunitake, T., Orientation and Spectral Characteristics of the Azobenzene Chromophore in the Ammonium Bilayer Assembly. Ber. Bunsenges. Phys. Chem. 1983, 87 (12), 1134-1143.

12. Friebolin, H., Ein- und zweidimensionale NMRSpektroskopie. 4 ed.; Wiley-VCH: Weinheim, 2006; p 304.
13. Israelachvili, J. N.; Mitchell, D. J.; Ninham, B. W., Theory of self-assembly of hydrocarbon amphiphiles into micelles and bilayers. J. Chem. Soc., Faraday Trans. 2 1976, 72, 1525 - 1568.

14. Gamboa, C.; Rios, H.; Sepulveda, L., Effect of the nature of counterions on the sphere-to-rod transition in cetyltrimethylammonium micelles. J. Phys. Chem. 1989, 93 (14), 5540-5543.

15. Blayo, C.; Houston, J. E.; King, S. M.; Evans, R. C., Unlocking Structure-Self-Assembly Relationships in Cationic Azobenzene Photosurfactants. Langmuir 2018, 34 (34), 10123-10134.

16. Zhu, M.-Q.; Zhang, G.-F.; Li, C.; Aldred, M. P.; Chang, E.; Drezek, R. A.; Li, A. D. Q., Reversible Two-Photon Photoswitching and Two-Photon Imaging of Immunofunctionalized Nanoparticles Targeted to Cancer Cells. Journal of the American Chemical Society 2011, 133 (2), 365-372.

17. Cabré, G.; Garrido-Charles, A.; Moreno, M.; Bosch, M.; Porta-de-la-Riva, M.; Krieg, M.; Gascón-Moya, M.; Camarero, N.; Gelabert, R.; Lluch, J. M.; Busqué, F.; Hernando, J.; Gorostiza, P.; Alibés, R., Rationally designed azobenzene photoswitches for efficient two-photon neuronal excitation. Nature Communications 2019, 10 (1), 907.

18. Arechabala, B.; Coiffard, C.; Rivalland, P.; Coiffard, L. J. M.; Roeck-Holtzhauer, Y. D., Comparison of cytotoxicity of various surfactants tested on normal human fibroblast cultures using the neutral red test, MTT assay and LDH release. J. Appl. Toxicol. 1999, 19 (3), 163 165.

19. Yamamoto, M.; Matsumura, R.; Hirata, Y.; Nagamune, H., A comparative study of skin irritation caused by novel bis-quaternary ammonium compounds and commonly used antiseptics by using cell culture methods. Toxicol. In Vitro 2019, 54, 75-81.

20. Hubner, N. O.; Siebert, J.; Kramer, A., Octenidine dihydrochloride, a modern antiseptic for skin, mucous membranes and wounds. Skin Pharmacol. Physiol. 2010, 23 (5), 244-58.

21. Cole, M. R.; Li, M.; El-Zahab, B.; Janes, M. E.; Hayes, D.; Warner, I. M., Design, Synthesis, and Biological Evaluation of beta-Lactam Antibiotic-Based Imidazolium- and Pyridinium-Type Ionic Liquids. Chem Biol Drug Des 2011, 78 (1), 33-41.

22. Hough-Troutman, W. L.; Smiglak, M.; Griffin, S.; Reichert, W. M.; Mirska, I.; Jodynis-Liebert, J.; Adamska, T.; Nawrot, J.; Stasiewicz, M.; Rogers, R. D.; Pernak, J., Ionic liquids with dual biological function: sweet and anti-microbial, hydrophobic quaternary ammoniumbased salts. New J Chem 2009, 33 (1), 26-33. 
SYNOPSIS TOC

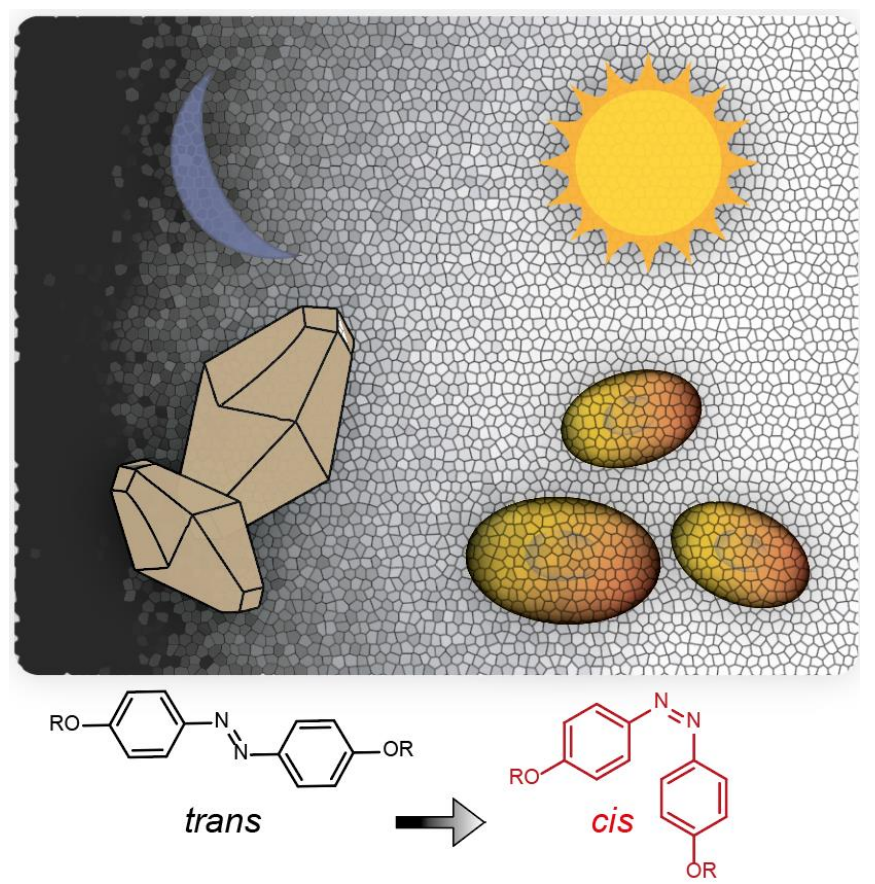

1. Mitscherlich, E., Ueber das Stickstoffbenzid. Ann. Pharm. 1834, 12 (2-3), 311-314.

2. Bandara, H. M.; Burdette, S. C., Photoisomerization in different classes of azobenzene. Chem. Soc. Rev. 2012, 41 (5), 1809-25.

3. Sadovski, O.; Beharry, A. A.; Zhang, F.; Woolley, G. A., Spectral tuning of azobenzene photoswitches for biological applications. Angew. Chem. Int. Ed. Engl. 2009, 48 (8), 1484-6.

4. Rodríguez-Soacha, D. A.; Decker, M., Photopharmacology in Alzheimer's Disease. Adv. Ther. 2018, 1 (3), 1800037 (1of 9).

5. Hull, K.; Morstein, J.; Trauner, D., In Vivo Photopharmacology. Chem. Rev. 2018, 118 (21), 10710-10747.

6. Ju, H.; Zhang, Y.; Zhang, Y.; Song, G.; He, Y.; Zhang, X.; Liu, Y., A DNA-Azobenzene Nanopump Fueled by Upconversion Luminance for Controllable Intracellular Drug Release. Angew Chem Int Ed Engl 2019.

7. Bi, Y.; Wei, H.; Hu, Q.; Xu, W.; Gong, Y.; Yu, L., Wormlike micelles with photoresponsive viscoelastic behavior formed by surface active ionic liquid/azobenzene derivative mixed solution. Langmuir 2015, 31 (13), 3789-98.

8. Ishiba, K.; Morikawa, M.-a.; Chikara, C.; Yamada, T.; Iwase, K.; Kawakita, M.;

Kimizuka, N., Photoliquefiable Ionic Crystals: A Phase Crossover Approach for Photon Energy Storage Materials with Functional Multiplicity. Angewandte Chemie 2015, 127 (5), 1552-1556.

9. $\quad$ Dugave, C.; Demange, L., Cis-trans isomerization of organic molecules and

biomolecules: implications and applications. Chem Rev 2003, 103 (7), 2475-532.

10. Choi, Y.-J.; Kim, J.-T.; Yoon, W.-J.; Kang, D.-G.; Park, M.; Kim, D.-Y.; Lee, M.-H.; Ahn, S.-k.; Jeong, K.-U., Azobenzene Molecular Machine: Light-Induced Wringing Gel Fabricated from Asymmetric Macrogelator. ACS Macro Lett. 2018, 7 (5), 576-581.

11. Shimomura, M.; Ando, R.; Kunitake, T., Orientation and Spectral Characteristics of the Azobenzene Chromophore in the Ammonium Bilayer Assembly. Ber. Bunsenges. Phys.

Chem. 1983, 87 (12), 1134-1143.

12. Friebolin, H., Ein- und zweidimensionale NMR-Spektroskopie. 4 ed.; Wiley-VCH:

Weinheim, 2006; p 304. 
13. Israelachvili, J. N.; Mitchell, D. J.; Ninham, B. W., Theory of self-assembly of hydrocarbon amphiphiles into micelles and bilayers. J. Chem. Soc., Faraday Trans. 2 1976, 72, $1525-1568$.

14. Gamboa, C.; Rios, H.; Sepulveda, L., Effect of the nature of counterions on the sphereto-rod transition in cetyltrimethylammonium micelles. J. Phys. Chem. 1989, 93 (14), $5540-$ 5543.

15. Blayo, C.; Houston, J. E.; King, S. M.; Evans, R. C., Unlocking Structure-Self-Assembly Relationships in Cationic Azobenzene Photosurfactants. Langmuir 2018, 34 (34), 1012310134.

16. Zhu, M.-Q.; Zhang, G.-F.; Li, C.; Aldred, M. P.; Chang, E.; Drezek, R. A.; Li, A. D. Q., Reversible Two-Photon Photoswitching and Two-Photon Imaging of Immunofunctionalized Nanoparticles Targeted to Cancer Cells. Journal of the American Chemical Society 2011, 133 (2), 365-372.

17. Cabré, G.; Garrido-Charles, A.; Moreno, M.; Bosch, M.; Porta-de-la-Riva, M.; Krieg, M.; Gascón-Moya, M.; Camarero, N.; Gelabert, R.; Lluch, J. M.; Busqué, F.; Hernando, J.; Gorostiza, P.; Alibés, R., Rationally designed azobenzene photoswitches for efficient twophoton neuronal excitation. Nature Communications 2019, 10 (1), 907.

18. Arechabala, B.; Coiffard, C.; Rivalland, P.; Coiffard, L. J. M.; Roeck-Holtzhauer, Y. D., Comparison of cytotoxicity of various surfactants tested on normal human fibroblast cultures using the neutral red test, MTT assay and LDH release. J. Appl. Toxicol. 1999, 19 (3), 163165.

19. Yamamoto, M.; Matsumura, R.; Hirata, Y.; Nagamune, H., A comparative study of skin irritation caused by novel bis-quaternary ammonium compounds and commonly used antiseptics by using cell culture methods. Toxicol. In Vitro 2019, 54, 75-81.

20. Hubner, N. O.; Siebert, J.; Kramer, A., Octenidine dihydrochloride, a modern antiseptic for skin, mucous membranes and wounds. Skin Pharmacol. Physiol. 2010, 23 (5), 244-58.

21. Cole, M. R.; Li, M.; El-Zahab, B.; Janes, M. E.; Hayes, D.; Warner, I. M., Design, Synthesis, and Biological Evaluation of beta-Lactam Antibiotic-Based Imidazolium- and Pyridinium-Type lonic Liquids. Chem Biol Drug Des 2011, 78 (1), 33-41.

22. Hough-Troutman, W. L.; Smiglak, M.; Griffin, S.; Reichert, W. M.; Mirska, I.; JodynisLiebert, J.; Adamska, T.; Nawrot, J.; Stasiewicz, M.; Rogers, R. D.; Pernak, J., lonic liquids with dual biological function: sweet and anti-microbial, hydrophobic quaternary ammoniumbased salts. New J Chem 2009, 33 (1), 26-33. 